\title{
Chapter 5 \\ Who Benefits from the Public Good? \\ How OER Is Contributing to the Private Appropriation of the Educational Commons
}

\section{Tel Amiel, Ewout ter Haar, Miguel Said Vieira, and Tiago Chagas Soares}

\begin{abstract}
The idea of Open Educational Resources (OER) has a history and is embedded in social contexts that influence its practice. To get a handle on tensions between different conceptualizations of "open" we discuss some of the battles surrounding the usage of the term. We note the origin of the concept of OER and how the emergence of the OER movement fits into the discourse of educational improvements through technologies and techniques. We argue that there is a relation between an uncritical stance toward technology and the appropriation of education activities by private oligopolies, a phenomenon that could be mitigated by a larger awareness of recent history and current sociotechnical analysis. We point out how these dilemmas play out in the Brazilian context of the implementation of OER in public policies and conclude by mentioning some programs and projects that point to the way forward.
\end{abstract}

Keywords Open educational resources $\cdot$ Open education $\cdot$ Private sector

\footnotetext{
T. Amiel (凷

University of Brasília (UnB), Campus Universitário Darcy Ribeiro, Faculdade de Educação, Cep: 70.910-900 Brasilia, Brazil

e-mail: amiel@unb.br

E. ter Haar

Universidade de São Paulo, Instituto de Física - USP, Rua do Matão 1371, CEP 05508-090

Cidade Universitária, São Paulo, Brazil

e-mail: ewout@usp.br

\section{S. Vieira}

Universidade Federal do ABC, Av. dos Estados 5001, 09210-580 Santo André, São Paulo, Brazil e-mail: miguel.vieira@ufabc.edu.br

\section{T. C. Soares}

Universidade de São Paulo, Rua Antônio João Tonella 179, Bosque de Barão Geraldo, CEP 13082-756 Campinas - SP, Brazil

e-mail: tiago@oplanob.com 


\subsection{Introduction}

In 1945, the magazine The Atlantic published an essay named "As We May Think" (Bush, 1945). Its author was Vannevar Bush, the then Director of the Office of Scientific Research and Development of the US Government. Bush had been responsible for the bulk of the technoscientific effort led by the US throughout World War II, an effort that led to a deep restructuring of how the country's research would be developed and networked from then on (Turner, 2010).

After World War II, with the Allied victory over the nazi-fascist threat, Bush was faced with a new and immediate challenge: to reconfigure, in peacetime, the sociotechnical apparatus mobilized at wartime. In a world struggling to be rebuilt from scratch, how should one set in motion a new architecture where information and science would foster individual freedom and the emancipation of knowledge? The answer sketched by Bush in his essay addresses this challenge through a new, radical rationale for cataloging, storing, and accessing of information. A system, that in its ideal form, would envision terminals to large repositories granting open access, at different levels of retrieval, to the whole of human knowledge-in print, audio, and film alike. To this networked, universal library, Bush gave the name Memex. The notion articulated by Bush in his Memex — of high technique as something in service of knowledge made universal-underlies, to some extent, what the internet came to be perceived as in the public imagination.

In the second half of the twentieth century, access to information and knowledge has taken the forefront of civic discourse and in the development and emancipation of individuals and communities alike. The emergence and fast development of computers, from the large mainframes of the 1960s to individual networked terminals, has opened a universe of possibilities intertwining the social and the technical. Through ideals such as free software, open source, copyleft, and remix culture, access to knowledge more often than not comes to mean also the mastery of new digital tools.

With the widespread expansion of the commercial Internet and the emergence of the World Wide Web from the 1990s onward, the centrality of the internet for the circulation of knowledge and in the transformation of educational practices fueled high expectations. This was theorized by authors who would become canonical of an optimistic outlook, including Castells (2011), Levy (2010), and Negroponte (1995). This ethos would become institutionalized in initiatives such as the W3C, articulating the civil society as a guardian of the internet in its technical and policy aspects.

In 2001, amidst this movement to institutionalize new standards, best practices, and joint objectives, the Massachusetts Institute of Technology (MIT) made the decision to open up teaching content through an online platform (Taylor, 2007). The initiative was copied by multiple other institutions, in what is sometimes referred to as the beginning of the Open Educational Resources (OER) movement. The terminology was consolidated during a 2002 UNESCO forum on educational resources (UNESCO, 2002), which evolved during the next decade into OER being defined as:

Learning, teaching and research materials in any format and medium that reside in the public domain or are under copyright that have been released under an open 
license, that permit no-cost access, re-use, re-purpose, adaptation and redistribution by others (UNESCO, 2019).

The OER movement has joined other efforts on the opening up of information, culture, and knowledge. Platforms such as Wikipedia and YouTube have become synonymous with shared knowledge creation and the democratization of access to educational content. Creative Commons (CC), a set of free licenses that has quickly become the global standard for free culture, and almost synonymous with "openness", is the license suit that is most used by these and other services in a converging movement between platform expansion and growth of open licensing initiatives.

According to official CC data, the number of resources made available with its licenses has grown from 140 million in 2006 to over 1 billion in 2016. Such expansion at first glance points to a huge increase in size, capillarization, and practices informed by the idea of OER. Notwithstanding some criticism of the methodology used to calculate the number of works with CC licenses (Downes, 2015), the movement has indeed grown, which is evident not only from its sheer number of cultural artifacts, but also from the number of licensed open access journals using CC licenses, and the political movement fostered by OER initiatives around the world. ${ }^{1}$ In Brazil, the public sector (at the federal, state, municipal, and institutional levels alike) has been mobilized to enable public policies in OER, with significant successes (Amiel, Gonsales, \& Sebriam, 2018). In fact, in a recent survey (Amiel \& Soares, 2016), the state seems to be, at least in Latin America, the main catalyst in the construction of projects, policies, and initiatives to make educational resources available.

In light of these principles and goals, it can be hard to find someone who is against the idea of "open". But to what extent such an idea, as well as the movement it has set into motion, is free of tensions and unimpeded by roadblocks? What are the possible gaps and breaches that could be found in these movements' multiple possibilities of implementation, debate, and elaboration? And to what extent could these methods and tools serve as tools of liberation while they promote practices which are undesirable to specific educational communities?

In this paper, we focus on these issues by examining the practices of OER. In doing so, we find ourselves obliged to bring out the way different areas associated with openness relate to each other, and to address issues usually ignored by those who (like us) advocate for OER. We begin our discussion by discussing the concept of "open" in different spheres and the general context of the battle surrounding the usage of the term. We follow with brief notes on the origin of the concept of OER and how the OER movement fits-from a historical perspective-into the discourse of educational improvements through technologies and techniques, and-in the current scenario-into the phenomena of the appropriation of education activities by private oligopolies. We point out some Brazilian dilemmas in the implementation of OER in public policies and end up by mentioning some programs and projects that point us to fruitful paths.

\footnotetext{
${ }^{1} \mathrm{~A}$ source of multiple policy initiatives is the OER World Map (http://www.oerworldmap.org).
} 


\subsection{The Battle for Open}

The construction of the public sphere in the second half of the twentieth century was based on technology, in particular on the new promises of Information and Communication Technology (ICT), that would enable the free expression of ideas. This project was seen in the light of liberal ideals, being a sort of vaccine against the emergence of the erosion of democracy and authoritarian power. Thinkers like Popper (2002) and Kuhn (2012) constructed models of the advancement of science that pointed to equality of access to knowledge and the tools for acquiring it as essential tools for liberty. But this kind of discourse, structured around ideals of equality and openness can be misleading when the political and economic assumptions of "open" projects must be given concrete meaning, when actors have to make sense of conflicting goals, means and results (Hansen \& Reich, 2015).

Weller (2015) suggests that there's a (metaphorical) battle being waged on the meaning of the word "open", when it comes to the internet and cyberculture in general. As certain interpretations gain hold, actors with countervailing interests try to modify and bend these meanings toward their own ends. One example is "openwashing" : the use of the expression "open" by actors, generally corporate market participants working with a profit motive, that wish to associate themselves with the positive connotations of the concept but without adopting the collaborative and transparent practices that are also typically associated with it. One example would be organizations that advertise open courses without permitting the reuse of course materials, or only as samples of commercial materials.

At stake in the battle for the meaning of "open" is the conception of what is a common good and who the commons serves. One answer to the phenomenon of openwashing is creating bright-line, rigid definitions that separate open from nonopen. ${ }^{3}$ A legalistic approach certainly gives clarity to the actors involved and aids policymaking. But these definitions are inevitably made in certain situated, local and political contexts, for certain ends. Being rigid, these rules may not attend to the needs of other communities at different times and contexts. And, as we shall see, even rigid rules can't always impede the subversion of the commons by outside interests.

Although there is a battle for its meaning, the adjective "open" in technical contexts still refers mostly to the collaborative or collective aspects of the production of digital goods. One of the most influential analyses of the sociotechnical possibilities of digital and internet technologies is the book The Wealth of Networks by Benkler (2006), in which he coined the expression commons-based peer production. Among

\footnotetext{
${ }^{2} \mathrm{An}$ expression that derives from greenwashing is used to describe practices that look like they are ecological and sustainable but in reality are not.

${ }^{3}$ See, for example, the definition of open at http://opendefinition.org, or, for OER, the " $5 \mathrm{R}$ " criteria that was created by one of the pioneers of the OER movement to precisely open content (http://www. opencontent.org/definition/). Some even identify open with the use of particular Creative Commons license such as CC-BY: https://open.bccampus.ca/2016/11/04/open-textbook-communityadvocates-cc-by-license-for-open-textbooks/.
} 
the set of practices to which this concept refers are those adopted by communities responsible for the production of commons and public goods like Wikipedia, or open and/or free software like the code for the Apache Web server. Similarly, most early participants in the OER movement were motivated by the idea that OER could contribute to social justice and that the practices associated with the "open" ethos would fit in naturally with educational theories and values like collaboration, transparency, horizontality, and other values of the commons.

But there is another side to the concept of open, not less powerful in its capacity to mobilize attention. Where Benkler emphasizes collaboration, and the empowerment of local communities through the commons, other proponents of open practices defend its role in efficiency gains and interoperability, concepts that are associated with traditional market mechanisms (cf. Evangelista, 2010). For example, in the area of transparency and open government, calls for more openness are targeted differently for audiences with different political outlooks. For a conservative audience focused on so-called free markets and traditional liberal and individual rights, open advocacy can emphasize the economic efficiency gains of initiatives like opening government data to market actors. For this audience, open government fits in perfectly with an ideology of the minimal state and free markets. But at the same time, open government advocacy can also be targeted to people with other political convictions, for example as being about the empowerment of civil society, favoring participatory democracy and the collective construction of common services. ${ }^{4}$ If the same concept is capable to serve to rhetorical necessities of both sides of the political spectrum, the question arises: for whom and to what end the expression "open" is being put into play?

It's commonplace — at least in the social sciences - to affirm that technologies are not neutral, that their use and meaning is at least in part political (Winner, 1993). Analogously, we can say that the concept of "open" and the sociotechnical discourses around it are loaded with political values, even though these are not expressed explicitly. Technologies, especially complex ones like those that mediate the creation and dissemination of cultural products, cannot be considered to be mere tools that can be used for good or for bad purposes. These technologies have structure, they facilitate certain uses and discourage others. Therefore, if open government can be used to advance distinct political and economic models, then the idea of "open" in education should also be analyzed critically with respect to the underlying assumptions that influence its goals and results. Open licenses, in particular, can be seen as a kind of legal technology that needs to be interrogated in this manner.

To show that these considerations are not merely theoretical, we now exemplify the risks of not doing the necessary critical analysis by pointing to some cases in areas that directly inspired the OER movement: open access, open source, and open culture in general.

Wikipedia is the canonical example of how the internet made possible large scale collaborative processes. Its success is undeniable in terms of volume of the material produced, and to a lesser extent in terms of its quality. However, research has shown that the project suffers from a lack of diversity of its contributors which in turn is

\footnotetext{
${ }^{4}$ See, for example, the Open Government Partnership (https://www.opengovpartnership.org/).
} 
reflected in the kinds of content produced. Large biases exist toward content that is of interest to a certain kind of audience: young, white men (Simonite, 2013).

The same lack of diversity exists among the contributors of open source software, to an even larger extent than in the IT industry as a whole. ${ }^{5}$ The GNU/Linux operating system is a project that, at the beginning of the century, was seen as a model of production independent of traditional systems of property rights and markets. Today, however, most contributions to the project are made by IT professionals employed by and working in the interest of large companies (Yegulalp, 2014). Open source and internet technologies certainly brought new distributed and collaborative models to the corporate world. But companies took from the original vision of commonsbased peer production only the parts that made their processes of accumulation more efficient. In many of these projects the formal equality of opportunity does not translate to real equality of participation. Not only do inequalities remain, in the absence of active interventions they are even amplified in some important dimensions.

A last case, especially relevant to the OER movement, is the subversion of the ideas and proposals of the open access movement by commercial publishers of scientific journals. Many publishers have used their monopoly on editorial validation to maintain control of the scholarly communication infrastructure, re-configuring their business models to slowly adapt to the latter, not the spirit, of open-access public policies. They have been able to articulate a model in which authors and funding agencies pay to publish while keeping prices high through artificial scarcity, marketing in prestige quantified through citation metrics. The resulting competition and the natural concentrating effect of market dynamics keep control over scholarly communication in the hands of just a few private actors. In the emerging "author pays" model, the price paid for the benefit of open access licensed scholarly articles is the exclusion of those academics without the capability to get funding to publish. The model also leads to conflicts of interests in the peer-review process and creates opportunities for bad actors to promote so-called predatory journals that publish without due regard for peer-review and academic merit. The open-access case is a prime example of how a narrow emphasis on the legal technology of licenses distracts from the real issue at hand, in this case the essential tension between public and private control over scholarly communication.

It's important to note that the collateral effects noted in the cases above are not caused by the projects and movements being "open" (in the sense of being participatory, collaborative, and culturally progressive). What the examples show is that without expressing clearly the meaning and goals of their "open" values, the movements are at the mercy of the status quo.

\footnotetext{
${ }^{5}$ For a general analysis of this matter see (Nafus, 2012). Three studies (David, Waterman, \& Arora, 2003; Ghosh, Glott, Krieger, \& Robles, 2002; Kuechler, Gilbertson, \& Jensen, 2012) found a 1-2 $\%$ participation rate of women in free software projects; a fourth study found a rate of $11 \%$, but presented selection bias, as admitted in the study (Arjona-Reina, Robles, \& Dueñas, 2014). These numbers are low, even compared to the small fraction of women in the IT industry as a whole, estimated to be $26 \%$ in the US (Ashcraft, McLain, \& Eger, 2016).
} 
Open licenses alone are insufficient to promote social justice, to create a commons or even just to achieve economic efficiency. Claiming openness does not automatically call into being a neutral or progressive space free of political tensions. Without explicitly addressing their political values, open movements are at risk to have these values subverted. If a project seeks to promote social justice, for example, it will need to take into account existing power relations between relevant actors. Without recognizing existing social inequalities, providing access, providing equal opportunities, or "democratizing" technology will not be effective and can even amplify these inequalities.

\subsection{The Battle for OER}

Open education and OER are ideas with great protagonism in discussions surrounding the future of education. Issues related to the personalization of teaching in online platforms, the digitization of teaching material, access to online practice exams, and online tutoring videos, among others, are promoted with a common message of equity and access to education for all. On the one hand, these resources can help promote the "hacker ethic" in education (Pretto, 2012) with an emphasis on questioning, criticality, remixing, recombination, and collaboration. On the other hand, the democratization of access to educational resources has been used to promote an education centered on the logic of efficiency and training of students for specific tasks, so that they may, only instrumentally, overcome more efficiently the continuous certification from basic to higher education. OER as we know it, a child of the web, is permeated by the historical tensions we have presented. It is important to sketch a brief history of the concept in order to understand why, despite arguments for their educational benefits that appeal to common sense, we chose to say that we are in a "battle for OER".

Online learning, and in particular "Learning Objects" (LO) gained much attention during the $90 \mathrm{~s}$ with the web and the rise of resource-based-learning (Hannafin \& Hill, 2008). LOs are small educational resources, usually focused on a single learning objective, designed so as to be combined with other resources to create a larger entity, focusing on a particular context of use. According to this logic, a small set of educational resources would be able to be used and reused in many different contexts (Downes, 2001). Some authors have emphasized the use of LOs in constructivist environments (Wiley, 2001); others have emphasized that in their actual implementations LOs were more naturally used in instructionist teaching with a training perspective (Friesen, 2004).

As Benkler (2005) points out, the use of repositories of small adaptable LOs to form a larger and contextualized collection would be appropriate for the type of education in which educators have autonomy to curate and select their own teaching materials. This scenario is more typical in higher education, with a professional creating a singular experience for students. How educators in other contexts-with more rigid institutional constraints, less technical support, limited digital competencies, 
among other factors-could make use of repositories was an important question for LOs (Sicilia \& Garcia, 2003). This remains the case today for OER.

On the other side of the modularity spectrum, that of textbooks and completes courses, Benkler also points to possible difficulties of applying his model of commons-based peer production, explaining that this model works best for resources with some natural modularity (like the encyclopedia entries of Wikipedia). The collaborative nature of peer production concept may be difficult to apply to resources that must conform to externally imposed quality standards, that are large volumes expected to maintain coherence or that need a distinct authorial voice (Benkler, 2005). We think that many of these concerns surrounding the use of LOs and debates around adequate policies for their adoption in educational environments should continue to be discussed as relevant agendas in the OER movement.

The introduction of new forms of educational technology, such as LOs and OER, is often seen as an obvious or inevitable development — or a sign of social progress. Examples of this mentality include the contested concept of the "digital natives"; the now largely debunked idea that Massive Open Online Courses (MOOCs), often associated with OER, would absolutely transform higher education ${ }^{6}$; and the idea that education through personalized algorithms would make teachers more efficient or even obsolete. For each of these narratives, convincing counter-arguments exist. Specialists have demonstrated the inadequacy and the lack of evidence for the idea of a "generational difference" associated to growing in an environment saturated by the internet (An \& Carr, 2017; Reeves \& Oh, 2008). The availability of many educational resources and courses from renowned universities online soon gave way to the recognition that education is more than transmitting and optimizing the delivery of lectures, no matter how charismatic the teacher may be. Finally, critics have indicated that behind the automation of the classroom there often is a deskilling (Chakraborty, 2013) of the job of the teacher, and a promotion of an instrumental perspective on education directed at the job market, in line with theories of learning focused on training instead (and sometimes with disregard) of the development of full citizenship. In each of these examples, one is able to identify commercial interests by vendors of educational technologies who might be less transparent than necessary about their motivations.

And so, what we have here is another view of OER, one that leads to caution. We cannot assume that the undeniable pedagogical potential of OER will naturally lead to changes that are aligned with pedagogical and political objectives, whichever these might be. Of course, association is not causation and the realization that educational technologies might have been poorly used in the past should not lead us to have preconceived notions in regard to OER. Nevertheless, the overly optimistic expectations of LOs, MOOCs, and educational technology, in general, should lead to caution with regard to how OER will be used in educational settings. We once again emphasize need to deploy educational technologies with a clear vision as to

\footnotetext{
${ }^{6}$ In a Wired article, Sebastian Thrun prophesied that in a near future there would only be 10 institutions providing higher education: https://www.wired.com/2012/03/ff_aiclass/.
} 
their risks and potentialities and the importance of having a well developed political and pedagogical vision. Without this, there is a risk that projects may naturally align themselves in directions that may diverge from what was originally intended. We continue below, with further examples that exemplify the tensions within the discourse around OER.

\subsubsection{OER and Oligopolies}

The fact that OER may appeal to different perspectives and economic interests helps us explain how the movement has diverged globally. The motivation for educational change is often associated with the conservatism of educational institutions, portrayed as traditional and lethargic - and always a target for radical change. Critics often point to old practices, inefficiency, and the resistance in updating practices as evidence of the lack of alignment of formal education to contemporary demands. Weller (2015) contextualizes this old and recurring critique, as part of the "Silicon Valley narrative", points out that the argument that "education is broken" has become such an acceptable point of view, that it has the semblance of hard truth (Weller, 2015, p. 2). Accepting this perspective opens up a path to "disruptive" change in contrast to incremental change in education.

Still, the educational literature demonstrates that, in fact, incremental change seems to the most consistent path to educational change (Tyack \& Cuban, 1997), and that the conservative nature of these institutions is only one side of the coin. Inbar (1996) argues that since public education has high level of permanence, guaranteed by a constant influx of students, funding and legislation, it might lead indeed to conservatism and inaction. On the other hand, these same guarantees create institutional safety, which can and (in many cases does) lead to an interest in innovation, change, and experimentation-but perhaps not as "disruptive" as some might wish.

Radical action is best exemplified by a Silicon Valley motto: "move fast and break things" which Dana Boyd recently characterized as "... an abomination if your goal is to create a healthy society" (Boyd, 2019). This mentality is often associated with the startup culture and the ecosystem surround what Smyrnaios (2016) considers and oligopoly perpetuated through large sums of capital and intellectual property: Google, Amazon, Facebook, Apple e Microsoft (GAFAM). Their aggressive focus on this market can be seen in all levels of formal education around the world. ${ }^{7}$

Singer (2017) indicates that, according to Google, more than half of all elementary school students in the United States (more than 30 million children) use Google applications, criticizing what she calls "Googlification" of the classroom. Brazil has moved in a similar direction. There is data that indicates a similar scenario in Brazil

\footnotetext{
${ }^{7}$ Within the \#GoOpen program in the USA, the implementation guide discusses the use of Google applications, see: https://tech.ed.gov/open/.
} 
(da Cruz, Saraiva, \& Amiel, 2019). ${ }^{8}$ Agreements and by-in from local governments have expanded and promoted access to GAFAM by schools. As an example, The São Paulo State Secretariat of Education regularly ${ }^{9}$ promotes its partnership with Microsoft, offering Office 365 free of charge to students, teachers, and managers, simply by creating an email through an official channel (Digital School Office, in free translation; SED), accessible only by using an account registered with Microsoft. The State Secretariat also established a partnership with Google to offer, through SED, access to the Google Education service. The scope of these partnerships is not restricted to the online space: to use the school's computer labs (named Acessa Escola), it is necessary to create an institutional email (a Microsoft account). This imposition effectively restricts the use of a public space and public equipment in a public institution; or at the very least, the imposition that one shares personal data to a foreign company to enjoy a public good.

In higher education, similar partnerships have taken effect, offering "free access" to services from companies such as Google and Microsoft. Access to these platforms is promoted as an added option to existing services, with an emphasis on being "free" and promoted as a clear benefit to higher education institutions. They do, however, ignore the costs of "free", its impact on the current software ecosystem in institutions, and the consequences of inducing the use of foreign corporate platforms, often in conflict with internal institutional policies (Parra, Cruz, Amiel, \& Marchado, 2018). The services offered go beyond email, and incorporate well-known productivity applications in the cloud (spreadsheets, text editors, etc.) as well as specific tools for education, such as grading sheets, shared calendars, activities, and tasks.

We have at least two potential scenarios. For some institutions, the partnership with companies might make "one more resource" available, that is, an alternative set of tools that in essence competes with existing solutions (such as a Moodle instance). In other cases, we begin to see evidence that the communication infrastructure of institutions is being taken over by companies such as Google and Microsoft, access to institutional communication tools (such as email) and file hosting (with institutional data) is no longer managed by higher education institutions. This stands in stark contrast to existing public or paid models that remain under the control of public administration (Parra et al., 2018). In both cases, given the economic power and the "free" provision of services offered by GAFAM, there is no room for effective competition with public entities, squashing the possibility of the coexistence of different platforms and services.

An almost inevitable consequence of this outsourcing of educational services is an atrophy in institutions and local educational businesses (unless aligned with larger corporate platforms), and the capacity to develop and support educational technology solutions that are adapted to local needs. As pointed out by Taplin (2017), antitrust

\footnotetext{
${ }^{8} \mathrm{Up}$ to date information on the Brazilian landscape is available in the Education Under Surveillance project website (educacaovigiada.org.br)

${ }^{9}$ See, for example: https://www.educacao.sp.gov.br/noticias/alunos-e-professores-podem-baixaro-pacote-office-365-da-microsoft-gratuitamente-2/ (2017); and https://www.educacao.sp.gov.br/ noticias/ferramentas-da-microsoft-facilitam-a-rotina-do-professor/ (2016).
} 
ideas from the 1960s and 1970s do not transfer well to the reality of twenty-first century informational markets. When products are "free" to the consumer, the real cost of monopolies is harder to ascertain.

As these services become institutionalized, and the de facto storage and communication systems, there is room for all sort of institutional information to be moved to these "partner" institutions: email exchanges between researchers, research data, personal student and teacher data, students grades and academic work, as well as (open) educational resources of all types. Google, for example, has said it does not use data from educational accounts for advertising purposes, ${ }^{10}$ educational accounts, though there is strong evidence that data is collected and processed in multiple forms. ${ }^{11}$ Privacy and copyright policies are notoriously difficult to navigate and understand. When these policies combine institutional regulation and private business policies, this becomes even more complicated (see Parra et al., 2018 for the description of two cases). When this partnership becomes institutionalized the acceptance of these policies is mandatory if one wants to use public services.

It is important to remember that beyond mining and collecting data, there are other ways in which businesses monetize "free". The continuous use of tools and platforms creates a cycle of familiarity and a content portfolio that created fidelity to the same platforms and tools in other areas of their life. In the words of the Head of Google Education for Brazil, "one of the advantages of offering services to schools is that we can create user fidelity early on" (Romani, 2019; our translation).

The voracity with which businesses such as Google and Microsoft (and Amazon, evidenced by their interest in OER through Amazon Inspire) promote their platforms to the educational sector leads us wonder how these "free" services benefit from usergenerated content and interaction, particularly educational resources? First, one must consider what constitutes an educational resource. Certainly, the lesson plans, books, presentations, quizzes and all sorts of resources that constitute the content of classes in proprietary platforms can be considered educational content. So it is worth asking: in what way does the production and dissemination of educational resources - in many cases OER - in closed or "free" platforms offered by large corporations contribute to the consolidation of these oligopolies? Keeping in mind the values of openness and transparency valued by OER, one should question how much its proponent contributes to the status quo when they suggest, induce or do not question the use of these platforms in their teaching or within their organizations. One could cite as examples the ability to easily connect content to Google Classroom from well-known sites like Currwiki and OER Commons. ${ }^{12}$

\footnotetext{
${ }^{10}$ See https://support.google.com/edu/classroom/answer/6025224?hl=en.

${ }^{11}$ See the "Spying on Student" report from the Electronic Frontier Foundation (EFF) at https:// www.eff.org/wp/school-issued-devices-and-student-privacy.

${ }^{12} \mathrm{See} \quad$ http://www.curriki.org/curriki-oer-library-is-now-lti-compliant-and-has-integrated-thegoogle-classroom-share-button/ and https://www.oercommons.org/authoring/13855-share-youroer-with-google-classroom/view.
} 
The intersection of OER and privacy is an emerging and still under-investigated field. The strategy supports the availability and capillarity of OER as they establish connections with platforms that control the distribution and storage of content. Another example of ambiguity is the partnership between Lumen Learning (headed by one of the pioneers of the OER movement in the United States of America) and Follett, "world's largest single source of books, entertainment products, digital content and multimedia for libraries, schools and retailers". ${ }^{13}$ This partnership could lead to increasing the visibility and use of open content through established channels while also reducing the plurality and diversity of players. One must also question the rhetoric that openness, when restricted to legal and licensing concerns, might actually lead to changes in education, beyond the possible reduction of cost.

It is still not possible to foresee the consequences of these partnerships and their role in the consolidation of existing oligopolies in these industries and their impact on privacy, control, and transparency. The same scenario can be seen in Brazil, as we will present next.

\subsection{Investigating Benefits and Risks}

It is important then, to reflect on the specific effects that an OER strategy can have on education. One of the most commonly used arguments I favor of OER is the reduction of costs to educational resources (for example, Fischer, Hilton, Robinson, \& Wiley, 2015). Educational resources are unquestionably important in any educational content, and have significant cost (in 2016, it was R $\$ 1,8$ billion-half of the National Fund for the Development of Education (FNDE) budget—and almost $2 \%$ of the Ministry of Educations' budget). With the upsurge of copyright legislation in recent decades, where rights reside mostly in the hands of publishers and conglomerates, the use of these resources is increasingly subject to restrictions-conditioned to authorization of payment-and frequently both.

Paradoxically, the influence of these restrictions is not limited to use and circulation of good, but also affect the production of these resources. For a small publisher that develops resources on literature, for example, it is increasingly difficult (and expensive) to include sections of literary works in their textbooks. ${ }^{14}$ OER allow for the creation of a collection of resources with fewer restrictions and have the potential to reduce the cost in both the starting and endpoints of this process: for the "final users" of educational resources and its initial producers.

This OER advantage is full of complexities and possible negative consequences that must not be dismissed lightly. We will examine two of these risks: the displacement of production, and the imbalance in the distribution of gains with the reduction of costs.

\footnotetext{
${ }^{13}$ See https://www.follett.com/lumen/.

${ }^{14}$ Benkler (2006, p. 37) attributed this situation to a characteristics of informational goods: fact that they are both outputs and inputs of creative work.
} 


\subsubsection{Production Offshoring}

The freedom to reuse OER can create two distinct situations in the development of textbooks. To exemplify those situations, let us imagine, a book on geography that contains some maps reproduced from other works (whose rights-holders demand authorization and royalties), and other maps that were produced specially for that book. In the first situation, which corresponds to reproduced maps, the use of OER would save costs on royalties, while also avoiding the need for authorization. In the second situation, the use of OER would save the costs of producing original maps.

It is in this second situation that relevant risks related to offshoring production arise. Although the cost savings that it allows could have positive effects, it also tends to encourage actors in peripheral countries to reduce their production of original material, replacing it by translating or merely reusing OER produced by actors in central countries, which will more frequently have the resources to produce original material. This trend can be particularly sharp in the commercial sector, since the actors making such use of OER will have a competitive advantage due to the cost savings. This can also imply the reduction of quality, in certain respects, of the materials produced. After all, even if the translated or adapted OER is of a very high pedagogical quality, it will rarely be able to reach the same level of context awareness (and meaningfulness to its public) than that of an original material produced by local experts, knowledgeable about the nuances of the sociocultural environment for which it is intended.

Although this trend is still relatively hypothetical, there are current examples that suggest it is important not to dismiss it. In Brazil, one of these examples can be seen in the parallel between the partnership negotiations between the Ministry of Education and the founder of Khan Academy for the translation of a vast amount of content in English, ${ }^{15}$ on the one hand, and the reduced amount and quality of digital materials purchased through the PNLD program ${ }^{16}$ on the other hand.

It is possible that this trend of concentration in content production-and in its related technical capabilities - may offer medium-term advantages to actors in large urban centers, and even to large local companies that follow this strategy; for instance, granting them dominance in those markets where existing OER are not a solution, or where there is a demand for complete educational systems (and not only for standalone educational material). It is nevertheless reasonable to consider if the availability of good quality, free to reuse educational resources would not compensate this asymmetry for under-resourced or peripheral actors. Without delving deeper in this debate, what seems beyond doubt is that there is no reason for the public sector to subsidize OER production by actors from large centers (or large local companies),

\footnotetext{
${ }^{15}$ This is only one of many translation projects supported by the Lemann Foundation. See http://www.fundacaolemann.org.br/khan-academy/ and http://www.fundacaolemann.org.br/paraaprender/.

${ }^{16}$ PNLD (National Program for Textbooks and Didactic Materials) is a federal program (one of the largest in the world) that buys textbooks from publishers and distributes them free of charge to schools.
} 
even more so if they can already obtain commercial advantages by doing so. What would make sense is subsidizing - or directing-OER production by peripheral or under-resourced actors. As Divardin and Amiel (2018) show, the pioneering purchase of digital multimedia resources under the PNLD in 2014 led to a restructuring and strengthening of existing players to cope with this novel demand. The structure of the call, associating the purchasing of multimedia to the usual print textbooks meant that the usual players acquired, outsourced or incorporated into their structures mechanisms for production of digital resources - the program tended to favor already dominant companies.

Before concluding this discussion about the risk of offshoring, a caveat should be added. The reasoning made here about this risk is somewhat simplified: we know there is an imprecise continuum - and not a binary distinction-between the production of original material, on the one hand, and reuse of an OER, on the other hand. It is thus perfectly possible to reuse OER in an authorly manner, adapting and remixing it creatively and with high context awareness. Similarly, the decontextualized use of translated and poorly adapted material is not a phenomenon brought about by OER, but rather a practice that already happened in the past. ${ }^{17}$ The production of original material is also not a panacea: it may well happen that an original material ends up being inferior to an existing OER, particularly with regard to its content or pedagogical approach. That, however, does not negate the fact that OER also open possibilities for more mechanical reuse practices, encouraging them by the cost reduction, and consequently introducing the risks of technical and pedagogical impoverishment (of the producers and resources, respectively) in subaltern regions and countries. Therefore, although the reasoning about the risk of offshoring should not be unduly generalized, and the particular circumstances of each case should be evaluated when discussing specific uses of OER, this argument also reveals a trend that can be problematic, particularly when considering its wide scale impacts.

\subsubsection{Concentration of Gains from Cost Reduction}

As mentioned above, the benefits that OER can offer to society must be weighed against the risks it implies, such as those from production offshoring. The second type of risk we will discuss involves the possibility that producers of educational resources might withhold those benefits, without sharing them with consumers or the public sector.

Indeed, in markets that are already concentrated (such as the textbook market in Brazil), competition might not be enough to force those who reduce costs (through

\footnotetext{
${ }^{17}$ Evidently the risk of lack of contextualization are not a issue only with OER. Contextualization has been a concern within the PNLD, through textbooks on History and Geography, for example. Still, looking at the recent 2016 purchase of these books, only 10 states were contemplated by specific texts (and some, like Mato Grosso do Sul and Espírito Santo were not even covered by more general textbooks, such as those who discussed the Amazon region or all of the Northeast (Brasil, 2015).
} 
the use of third party OER) to pass on such reductions to consumer prices. Thus, in the Brazilian example, it is possible that a growth in OER adoption among publishing houses participating in the PNLD might not represent a reduction in public spending with educational resources, or that such reduction is not a fair share of the savings those companies achieved in their costs; in that scenario, the social benefits brought by OER would be captured by publishing houses, and transformed into an increase in their profit margins.

One cannot deny that, on the one hand, OER generate an equalizing effect that allows to reduce an important barrier for the participation of small publishing houses in a government program as PNLD: the capital needed to invest in original material production (capital which smaller firms frequently do not have). It so happens, though, that this is only one of the many barriers that small publishing houses face in such programs. In PNLD, for instance, publishing houses are responsible for printing and distributing the works, tasks that demand a robust structure and sophisticated relationships with other companies, and that larger publishing houses are much more prepared to undertake. That causes a paradox: in case the equalizing effect of OER is not enough to allow smaller firms to compete effectively in PNLD, the possible concentrating effect of OER (which happens, as discussed in the previous paragraph, when the company captures the cost savings generated by the use of OER and turns into an increase of its profit margin) reinforces the asymmetry of this market, feeding back into the risk discussed here.

The example of the PNLD is not the only one in which this risk of private capture of OER benefits manifests itself; it can also be seen when the educational resource is not the final product to be commercialized, but an input in a larger "package". As such, it is also possible that, in for-profit education, a company may start adopting OER in order to save costs (making the production of textbooks that are already included in the tuition fees cheaper), but end up not passing on this cost reduction to consumer prices, but rather incorporating it in its profit margin.

In Brazil, that scenario is very feasible in higher education, which is another extremely concentrated sector in the country-the largest educational company in the world (Cogna, formerly known as Kroton Educacional) ${ }^{18}$ is Brazilian-as well as in the case of so-called "teaching systems", in which a company sells schools an ensemble of educational services (including not only textbooks, but also training, technological solutions, consulting, etc.), blurring the exact pricing of educational resources.

\footnotetext{
${ }^{18}$ The company became the largest in the world in 2014, after it merged with Anhanguera, another Brazilian educational company.
} 


\subsection{Finding Equilibrium}

The majority of the risks we identified here are related to the capture of the potential benefits of OER by private actors involved in the production of educational resources (or those who make use of them to offer educational services). Even though there is room for state activity in this sector, we do not wish to defend the idea that educational resources should be produced solely by public actors. Without entering the discussions on the comparative efficiency of the public and private sectors, it is difficult to imagine that the centralization of this production within the state's apparatus could produce the kaleidoscope of necessities of the Brazilian educational system. As it stands, the state already has substantial sway in large content distribution programs, such as the PNLD; even though the PNLD is an example of a program that favors diversity, we suspect that exacerbating this power in the hands of the state could be detrimental in the case of totalitarian regimes, or when progressive and democratic values might be trumped in favor of specific ideologies.

Exclusivity would also neutralize one of the great potentials of OER: finding new models for the production of educational resources, so that they may be treated as a common good. In other words, a model that would allow anyone that demands so, to have access to them, and that encourages and permits anyone to contribute to its improvement. The creation of this type of legislation, infrastructure, and benefits is within the reach of the public sector-mechanisms that might promote and protect this "commons" and to create policies that induce those actors who today are in a privileged status to adopt strategies that will nourish this commons and make capturing it more difficult.

Initiatives in this direction have already taken place. The call for PNLD 2019 and 2020 demand that a portion of the digital resources submitted by publishers be licensed openly. To take the latter as an example, all "extra" resources which are used by teachers (quizzes, lesson plans, etc.) and $75 \%$ of all audiovisual resources must have an open license (CC-BY-NC). A specific clause also allows for publishers to negotiate the complete (patrimonial) rights of submitted works, so that these rights are transferred to the Ministry of Education. ${ }^{19}$

While still recent and relatively small in scope, this proposal instigates a discussion on open licensing and distribution within the publishing industry, and promotes the availability of quality open content to the public without an expiration date on availability. It also opens up discussions on new models for the acquisition of educational resources with public monies, which might lead to a greater variety of participants in these calls and new models for purchasing content.

Within the Board for Distance Education (Diretoria de Ensino a Distância; DED/CAPES, which is responsible for the management of Open University of Brazil (Universidade Aberta do Brasil; UAB) there has been a strong and concerted effort in the direction of open resources. Since late 2016, all resources created by those receiving funds through the UAB (teachers, tutors, staff) must be openly licensed.

\footnotetext{
${ }^{19}$ Learn more at: http://aberta.org.br/materiais-educacionais-comprados-pelo-mec-terao-licencacreative-commons/.
} 
The UAB is a consortium of over 130 public institutions serving over 900 municipal centers throughout the country. ${ }^{20}$ This policy, coupled with training, workshops, and the creation of network of OER Ambassadors in over a dozen higher education institutions ${ }^{21}$ have created substantial momentum.

Another positive example is Ministry's new educational resources site for basic education. ${ }^{22}$ As a repository, it only accepts resources which are openly licensed. It also includes detailed terms of service, which has been created to be an instructional material that can help users and contributors understand the difference between free, closed, and open content.

Also within the federal level, the Science Cloud Computing platform is under development by the National Network for Teaching and Research (Rede Nacional de Ensino e Pesquisa; RNP). Among other services, RNP is piloting a solution for file sharing for public higher education institutions and government educational agencies in a public cloud. Even though it is not strictly an initiative for the sharing of educational resources, it demonstrates that creating public infrastructures for collaborative work is possible. The case is also interesting because it demonstrates how this infrastructure can integrate itself to a larger ecosystem not only for servers but also for clients. It is based on free and open-source software (OpenStack, Owncloud) for which the institution also made contributions to the code (Ribeiro Filho et al., 2015). These are just some of the recent initiatives that already do, or might soon impact how educational resources are purchased, shared and created, due in great part to the activism of public servants, civil society organizations, educators and researchers fighting for the common good.

\subsection{Conclusion}

One of our main goals with this chapter is to demonstrate that open educational resources, like all digital or online technologies, are not neutral or apolitical. If they don't make explicit their premises, projects or movements run the risk of finding themselves adrift, at the mercy of the winds existing powers. If technology is to provide educational and social benefits, and not mere efficiency gains or monetary gains, they should be configured explicitly for these ends. There are risks in applying the "open" concept in a naive way, especially when it's configured by incumbent market actors. The delocalization of the production of teaching materials, the concentration of profit, and the strengthening of the position of big corporations are examples of these risks. In a paradox characteristic of globalization, OER from "the center" become ubiquitous, leading to atrophy of the capacity of the periphery to produce and to disseminate its voice.

\footnotetext{
${ }^{20}$ Visualize a map of the institutions and the municipal centers here: http://uab.educacaoaberta.org/.

${ }^{21}$ See the official CAPES page on OER and the Ambassadors at: http://www.capes.gov.br/uab/rea/.

${ }^{22}$ See https://plataformaintegrada.mec.gov.br/. It functions both as a referatory to both open and closed content, and as a repository, hosting exclusively open content.
} 
When OER are financed by private interests and hosted on platforms owned by oligopolies that feed of their metadata and the personal data of their users, the mere possibility de jure of adaptation and remix won't save the local production of educational resources. A global commons that is structured on the terms of transnational corporations won't attend to the necessities of local communities of schools, educators, and students around the world.

OER and the ideas sustained by the various open movements like those of Open Access, Open Science, Transparency and Open Government or Open Data can and should be used to promote the autonomy of educators, a diversity of ideas and the creation of collaborative spaces. As pointed out by Peters and Britez (2008), OER mean freedom, citizenship, knowledge for all, social progress, and the transformation of individuals. Can a critical analysis of the project and an honest assessment of its limitations help realize the potential of this valuable movement for education? We sincerely believe so.

Acknowledgments If you wish to acknowledge persons who contributed or sponsoring agencies, do so here in this optional section.

\section{References}

Amiel, T., \& Soares, T. C. (2016). Identifying tensions in the use of open licenses in OER repositories. The International Review of Research in Open and Distributed Learning, 17(3). https:// doi.org/10.19173/irrodl.v17i3.2426.

Amiel, T., Gonsales, P., \& Sebriam, D. (2018). Recursos Educacionais Abertos no Brasil: 10 anos de ativismo. EmRede, 5(2), 246-258.

An, D., \& Carr, M. (2017). Learning styles theory fails to explain learning and achievement: Recommendations for alternative approaches. Personality and Individual Differences, 116, 410-416. https://doi.org/10.1016/j.paid.2017.04.050.

Arjona-Reina, L., Robles, G., \& Dueñas, S. (2014, January). The FLOSS2013 Free/Libre/Open Source Survey. Retrieved March 26, 2017, from http://web.archive.org/web/20140212132153/, http://floss2013.libresoft.es/results.en.html.

Ashcraft, C., McLain, B., \& Eger, E. (2016). Women in tech: The facts. Retrieved from https://www.ncwit.org/sites/default/files/resources/ncwit_women-in-it_2016-full-report_ final-web06012016.pdf.

Benkler, Y. (2005). Common wisdom: Peer production of educational materials. Retrieved from http://www.lemill.org/trac/raw-attachment/wiki/BookList/162436.pdf.

Benkler, Y. (2006). The wealth of networks: How social production transforms markets and freedom. New Haven [Conn.]: Yale University Press.

Boyd, D. (2019, September 17). Facing the great reckoning head-on. Retrieved September 20, 2019, from https://onezero.medium.com/facing-the-great-reckoning-head-on-8fe434e10630.

Brasil. (2015). Guia de livros didáticos: PNLD 2016: Apresentação: Ensino fundamental anos iniciais. Retrieved from http://www.fnde.gov.br/centrais-de-conteudos/publicacoes/category/125guias?download=9598:pnld-2016-guia-apresentacao.

Bush, V. (1945, July). As we may think. The Atlantic. Retrieved from https://www.theatlantic.com/ magazine/archive/1945/07/as-we-may-think/303881/.

Castells, M. (2011). The rise of the network society: The information age: Economy, society, and culture. New York: Wiley. 
Chakraborty, S. (2013). Deskilling of the teaching profession. In J. Ainsworth (Ed.), Sociology of education: An A-to-Z guide. https://doi.org/10.4135/9781452276151.n106.

da Cruz, R., Saraiva, F., \& Amiel, T. (2019). Coletando dados sobre o Capitalismo de Vigilância nas instituições públicas do ensino superior do Brasil. In VI Simpósio Internacional LAVITS. Presented at the LAVITS, Salvador. Retrieved from https://www.integra.unb.br/s/5zWiygrHPcXFitD.

David, P. A., Waterman, A., \& Arora, S. (2003). FLOSS-US the free/libre/open source software survey for 2003. Stanford Institute for Economic Policy Research, Stanford University, Stanford, CA (http://www.stanford.edu/group/floss-us/report/floss-us-report.pdf). Retrieved from https:// pdfs.semanticscholar.org/f040/542f2d2ab3c188fac82b5d039ad7aa31a97d.pdf.

Divardin, D., \& Amiel, T. (2018). A produção de contéudos digitais para o PNLD. In Proceedings of the XIII Latin-American Conference on Learning Technologies. Presented at the LACLO, São Paulo. Retrieved from http://cleilaclo2018.mackenzie.br.

Downes, S. (2001). Learning objects: resources for distance education worldwide. The International Review of Research in Open and Distributed Learning, 2(1). Retrieved from http://www.irrodl. org/index.php/irrodl/article/view/32.

Downes, S. (2015). State of the commons report. Retrieved January 26, 2017, from http://www. downes.ca/post/64762.

Evangelista, R. de A. (2010). Traidores do movimento: Política, cultura, ideologia e trabalho no Software Livre (Unicamp [dissertação de doutorado]). Retrieved from http://www.bibliotecadigital. unicamp.br/document $/$ code $=000477515$.

Fischer, L., Hilton, J., Robinson, T. J., \& Wiley, D. A. (2015). A multi-institutional study of the impact of open textbook adoption on the learning outcomes of post-secondary students. Journal of Computing in Higher Education, 27(3), 159-172.

Friesen, N. (2004). Three objections to learning objects and e-learning standards. In Online education using learning objects (pp. 59-70). London: Routledge.

Ghosh, R. A., Glott, R., Krieger, B., \& Robles, G. (2002). Free/libre and open source software: Survey and study. International Institute of Infonomics, University of Maastricht. Retrieved from http://www.math.unipd.it/ bellio/FLOSS\%20Final\%20Report\%20-\%20Part\%204\%20-\% 20Survey\%20of\%20Developers.pdf.

Hannafin, M., \& Hill, J. (2008). Resource-based learning. In M. Spector, D. Merrill, J. van Merrienboer, \& M. Driscoll (Eds.), Handbook of research in educational technology (3rd ed.). New York: Lawrence Erlbaum.

Hansen, J. D., \& Reich, J. (2015). Democratizing education? Examining access and usage patterns in massive open online courses. Science, 350(6265), 1245-1248. https://doi.org/10.1126/science. aab3782.

Inbar, D. E. (1996). Planning for educational innovation (Vol. 37). Retrieved from http://unesdoc. unesco.org/images/0011/001119/111952eb.pdf.

Kuechler, V., Gilbertson, C., \& Jensen, C. (2012). Gender differences in early free and open source software joining process. In Open source systems: Long-term sustainability (pp. 78-93). https:// doi.org/10.1007/978-3-642-33442-9_6.

Kuhn, T. S. (2012). The structure of scientific revolutions: 50th anniversary edition. Chicago: University of Chicago Press.

Levy, P. (2010). Cibercultura. Editora 34.

Nafus, D. (2012). "Patches don't have gender": What is not open in open source software. New Media \& Society, 14(4), 669-683. https://doi.org/10.1177/1461444811422887.

Negroponte, N. (1995). Being digital. Vintage Books.

Parra, H., Cruz, L., Amiel, T., \& Marchado, J. (2018). Infraestruturas, economia e política informacional: O caso do Google Suite for education. Mediações, 23(1), 63-99. https://doi.org/10.5433/ 2176-6665.2018v23n1p63.

Peters, M. A., \& Britez, R. G. (2008). Introduction: Open education and education for openness. In R. G. Britez \& M. A. Peters (Eds.), Open education and education for openness (pp. xvii-xxii). Taipei: Sense Publishers. 
Popper, K. R. (2002). Conjectures and refutations: The growth of scientific knowledge. London: Routledge.

Pretto, N. (2012). Professores-autores em rede. In B. Santana, C. Rossini, \& N. D. L. Pretto (Eds.), Recursos Educacionais Abertos: Práticas colaborativas e políticas públicas (pp. 91-108). São Paulo: Casa da Cultura Digital/Edufba.

Reeves, T. C., \& Oh, E. (2008). Generational differences. Handbook of Research on Educational Communications and Technology, 3, 295-303.

Ribeiro Filho, J. L., Nunes, A. C. F., Makino, R. N. dos S., Araújo, G. B., Martins, G. M. L., \& Guimarães, L. M. de O. (2015). Structuring and implementing the Brazilian Academic Cloud: Strategy, modelling, challenges and services. In Proceedings and Report of the 8th UbuntuNet Alliance Annual Conference. Presented at the 8th UbuntuNet Alliance annual conference, Maputo. Retrieved from http://www.ubuntunet.net/sites/default/files/Ribeiro\%20Filho.pdf.

Romani, B. (2019, February 17). Gigantes da tecnologia entram na briga por novo espaço: A sala de aula. Estado de São Paulo. Retrieved from https://link.estadao.com.br/noticias/culturadigital,gigantes-da-tecnologia-entram-na-briga-por-novo-espaco-a-sala-de-aula, 70002724698.

Sicilia, M.-A., \& Garcia, E. (2003). On the concepts of usability and reusability of learning objects. The International Review of Research in Open and Distributed Learning, 4(2). Retrieved from http://www.irrodl.org/index.php/irrodl/article/view/155.

Simonite, T. (2013). The fight to save wikipedia from itself. Retrieved August 29, 2017, from https:// www.technologyreview.com/s/520446/the-decline-of-wikipedia/.

Singer, N. (2017). How Google took over the classroom. New York Times, 13. Retrieved from https:// www.nytimes.com/2017/05/13/technology/google-education-chromebooks-schools.html.

Smyrnaios, N. (2016). L'effet GAFAM: stratégies et logiques de l'oligopole de l'internet (pre-print). Communication \& Langages, 2016(188), 61-83.

Taplin, J. (2017, April 22). Is it time to break up Google? Retrieved from https://www.nytimes.com/ 2017/04/22/opinion/sunday/is-it-time-to-break-up-google.html.

Taylor, J. C. (2007). Open courseware futures: Creating a parallel universe. Journal of Instructional Science and Technology, 10(1), 9.

Turner, F. (2010). From counterculture to cyberculture: Stewart brand, the whole earth network, and the rise of digital utopianism. Chicago: University of Chicago Press.

Tyack, D., \& Cuban, L. (1997). Tinkering toward utopia: A century of public school reform. Boston, MA: Harvard University Press.

UNESCO. (2002). UNESCO promotes new initiative for free educational resources on the internet. Retrieved from http://www.unesco.org/education/news_en/080702_free_edu_ress.shtml.

UNESCO. (2019). Draft recommendation on Open Educational Resources. Retrieved from https:// unesdoc.unesco.org/ark:/48223/pf0000370936.

Weller, M. (2015). MOOCs and the silicon valley narrative. Journal of Interactive Media in Education, 2015(1). Retrieved from http://jime.open.ac.uk/articles/10.5334/jime.am/.

Wiley, D. A. (2001). The instructional use of learning objects-Online version. Retrieved from http://www.reusability.org/read/.

Winner, L. (1993). Social constructivism: Upon opening the black box and finding it empty. In R. C. Sharff \& V. Dusek (Eds.), Philosophy of technology: The technological condition (pp. 233-243). Malden, MA: Blackwell.

Yegulalp, S. (2014, February 3). Who writes Linux? Corporations, more than ever. Retrieved August 29, 2017, from https://www.infoworld.com/article/2610207/open-source-software/who-writeslinux--corporations--more-than-ever.html.

Tel Amiel completed his Ph.D. in Instructional Technology at the University of Georgia. He is currently professor at the School of Education at the University of Brasília where he coordinates the UNESCO Chair in Distance Education (educacaoaberta.org). He was previously coordinated the UNESCO Chair in Open Education (Unicamp). More information at amiel.info. 
Ewout ter Haar obtained his Ph.D. in condensed matter physics from the University of Leiden. He works since 2006 with Educational Technology at the University of São Paulo.

Miguel Said Vieira is a professor at the Federal University of ABC (UFABC, Brasil), where he works at the Center for Educational Technologies and teaches in the Public Policies and Sciences and Humanities programs. His research deals with the relations between knowledge, technology, collaboration and commodification, with a special interest in the theme of commons (including theoretical approaches and specific practices such as OER, free software and open access), and the areas of STS and philosophy of science. His publications can be found at http://impropriedades. wordpress.com.

Tiago C. Soares holds a Ph.D. in History of Economics from the University of São Paulo. A longtime activist, he's been involved with the Open Education and Free/Libre and Open Source Software movements for nearly two decades. He is an associate with the UNESCO Chair in Distance Education (Universidade da Brasília).

Open Access This chapter is licensed under the terms of the Creative Commons Attribution 4.0 International License (http://creativecommons.org/licenses/by/4.0/), which permits use, sharing, adaptation, distribution and reproduction in any medium or format, as long as you give appropriate credit to the original author(s) and the source, provide a link to the Creative Commons license and indicate if changes were made.

The images or other third party material in this chapter are included in the chapter's Creative Commons license, unless indicated otherwise in a credit line to the material. If material is not included in the chapter's Creative Commons license and your intended use is not permitted by statutory regulation or exceeds the permitted use, you will need to obtain permission directly from the copyright holder. 